\title{
Prospective Sensemaking and Thinking Infrastructures in a Large-Scale Humanitarian Crisis
}

DOI:

10.1108/S0733-558X20190000062006

\section{Document Version}

Accepted author manuscript

Link to publication record in Manchester Research Explorer

\section{Citation for published version (APA):}

Gatzweiler, M. K., \& Ronzani, M. (2019). Prospective Sensemaking and Thinking Infrastructures in a Large-Scale Humanitarian Crisis. Research in the Sociology of Organizations , 62, 85-112. [4]. https://doi.org/10.1108/S0733558X20190000062006

\section{Published in:}

Research in the Sociology of Organizations

\section{Citing this paper}

Please note that where the full-text provided on Manchester Research Explorer is the Author Accepted Manuscript or Proof version this may differ from the final Published version. If citing, it is advised that you check and use the publisher's definitive version.

\section{General rights}

Copyright and moral rights for the publications made accessible in the Research Explorer are retained by the authors and/or other copyright owners and it is a condition of accessing publications that users recognise and abide by the legal requirements associated with these rights.

\section{Takedown policy}

If you believe that this document breaches copyright please refer to the University of Manchester's Takedown Procedures [http://man.ac.uk/04Y6Bo] or contact uml.scholarlycommunications@manchester.ac.uk providing relevant details, so we can investigate your claim.

\section{OPEN ACCESS}




\title{
PROSPECTIVE SENSEMAKING AND THINKING INFRASTRUCTURES IN A LARGE-SCALE HUMANITARIAN CRISIS
}

\author{
Marian Konstantin Gatzweiler, The University of Edinburgh Business School \\ Marian.Gatzweiler@ed.ac.uk
}

Matteo Ronzani, The University of Edinburgh School of Social and Political Sciences

\author{
mronzani@ed.ac.uk
}

\begin{abstract}
Authors Biographies
Dr Marian Gatzweiler's research focuses on the role of quantification and metrics as tools that actively shape organising processes and policy in response to grand social challenges. Rather than examining metrics as merely providing 'evidence' for managers and policy makers, his research places numbers and visualisations in the foreground to understand how notions of knowledge, innovation and accountability are constructed and practiced in such settings.
\end{abstract}

Dr Matteo Ronzani's research focuses on the roles of visualisations and material artefacts in processes of organising and on how metrics and indicators are implicated in the making of transnational governance. 


\begin{abstract}
In this study, we explore how thinking infrastructures can orchestrate collective sensemaking in unstable and socially contested environments, such as large-scale humanitarian crises. In particular, drawing from recent interest in the role of artefacts and infrastructures in sensemaking processes, we examine the evaluative underpinnings of prospective sensemaking as groups attempt to develop novel understandings about a desired but ambiguous set of future conditions. To explore these theoretical concerns, we conducted a detailed case study of the unfolding challenges of managing a large-scale humanitarian crisis response. Our study offers two contributions. Firstly, we develop a theorization of the process through which performance evaluation systems can serve as thinking infrastructures in the collaborative development of new understandings in unstable environments. Secondly, our study sheds light on the practices that support prospective sensemaking through specific features of thinking infrastructures, and we unpack how prospective and retrospective forms of sensemaking may interact in such processes.
\end{abstract}

Keywords: prospective sensemaking, thinking infrastructure, humanitarian crisis, performance evaluation 


\section{INTRODUCTION}

In this study, we explore how thinking infrastructures can orchestrate collective sensemaking in unstable and socially contested environments, such as large-scale humanitarian crises. Thinking infrastructures can be understood as the technologies and social practices that guide cognition and shape organizing work across distributed settings and temporal scales. However, as has been noted (see Weick \& Sutcliffe, 2015), during crises, thinking infrastructures are commonly experienced by way of their limitations, incompleteness, and failures. Such limitations may take the form of insufficient knowledge of system boundaries (Garud, Sanjay \& Tuertscher, 2008), ambiguities of choice (March, 1987), or shifting loci of control (Quattrone \& Hopper, 2005). Given that these elements constitute the norm rather than the exception in crisis settings, they provide challenging theoretical and practical problems for scholarly understanding of thinking infrastructures and sensemaking. In particular, the role of performance categorisations and reporting mechanisms is critical in the way organisations and decision-makers relate to unstable crisis settings (Boin, Hart, Stern \& Sundelius, 2005). That is because categorisations create specific forms of visibility and invisibility, which in turn induce blind spots that might miss unexpected events by labelling them too quickly as 'infamily', namely as events that had been previously observed and analysed (Weick, 2005). In other words, if thinking infrastructures draw attention away from important elements that are not captured by them, a resulting concern is an increased likelihood that these systems impede engagement with emergent issues before they amplify and become impossible to contain.

Therefore, in unstable settings a challenge for thinking infrastructures is to work against an overly strict focus on conforming to existing measures, and instead to stimulate engagement with anomalies and the unexpected through future-oriented inquiry. Despite some investigations into how technologies, such as accounting devices, may be implicated in procedures to engage with 'unknown unknowns' (Quattrone, 2015; March, 1987), create alternatives in decision-making (Mouritsen \& Kreiner, 2016), and envision futures (Miller \& O'Leary, 2007; Beckert \& Bronk, 2018), theoretical understanding of the role of such systems in collective processes of future-oriented sensemaking remains underdeveloped. In particular, little is known about the process through which thinking infrastructures can support the transition from unexpected early cues into new, refined understandings in fast-shifting environments. Accordingly, we investigate how specific features of thinking infrastructures can shape the collective development of new understandings to make sense of unstable settings, 
such as humanitarian emergencies, where the potentialities for disastrous errors are overwhelming.

To explore these concerns, we draw from recent developments in sensemaking theory, and particularly from a less investigated research stream on prospective sensemaking (Stigliani \& Ravasi, 2012; Maitlis \& Christianson, 2014). While sensemaking is mainly concerned with questions of how actors retrospectively rationalise their actions in an ongoing manner (Weick, Sutcliffe \& Obstfeld, 2005), prospective sensemaking focuses on future-oriented processes in which groups attempt to develop novel understandings about a desired, but only vaguely defined, set of conditions. Prospective sensemaking thus involves "the conscious and intentional consideration of the probable future impact of certain actions, and especially nonactions, on the meaning construction processes of themselves and others" (Gioia, Thomas, Clark \& Chittipeddi, 1994, p.378). Drawing from this emerging line of research, in this study we specifically focus on the interplay between prospective and retrospective forms of sensemaking as people attempt to construct new shared knowledge structures. In making this theoretical move, we seek to further build on and strengthen recent interest in the role of material infrastructures and artefacts as constitutive elements that shape sensemaking processes (Maitlis \& Christianson, 2014). While studies have begun to shed light on the way relatively mundane artefacts can form integral elements for prospective sensemaking (Stigliani \& Ravasi, 2012), little is known of the role of performance evaluation systems in such processes. The theoretical concerns of this study can thus be summarised as follows: What role may evaluation systems play as thinking infrastructures to guide processes of prospective sensemaking? Which features make thinking infrastructures influential in such prospective sensemaking processes?

To investigate the interrelations between thinking infrastructures and collective sensemaking processes, we conducted a detailed case study of evaluative practices in a refugee camp in the Middle East that was set-up to manage a humanitarian crisis, with tens of thousands of disaster-affected people depending on the camp's services. In particular, we follow interactions with a thinking infrastructure that was developed with the aim of facilitating engagement with the unpredictable nature of humanitarian crises: The Sphere evaluation handbook. Sphere is generally recognised as the most significant innovation in the area of humanitarian performance evaluation (Barnett, 2011; ECBC, 2007). Given that information infrastructures are commonly fragmented in humanitarian crises due to the instability of such settings, Sphere's handbook design was conceived so that humanitarian managers could carry 
it with them as an accessible and movable artefact that guides their thinking in all types of field operations. Accordingly, by relying on data collected through semi-structured interviews, shadowing, observations, and document analysis (Czarniawska, 2014), the research follows the humanitarian crisis managers in their attempts to make sense of, and build a reliable system, to distribute nutritional supplies. The delivery of nutritional items constitutes one of the essential elements of a humanitarian crisis operation, reaching deep into all aspects of life in refugee camps, including survival, health, well-being, cultural expectations, control, and politics. Exploring sensemaking challenges surrounding the issue of nutrition thus allows the research to follow one of the most significant and complex challenges in humanitarian responses. Our study argues that exceptional cases, such as humanitarian crises, can provide novel insights into management knowledge by offering a distinctive perspective to explore how people interact with thinking infrastructures to make sense of, and adapt to, unstable settings under significant pressure (Hällgren, Rouleau \& de Rond, 2018).

Our study offers two theoretical contributions. Firstly, we develop a theorisation of the process through which evaluation systems can serve as thinking infrastructures in the collaborative development of new knowledge constructs in unstable settings, such as humanitarian crises. Theorising from our empirical material, we conceptualise the interrelationship between the thinking infrastructure and sensemaking processes as unfolding in several different phases. These phases include fostering conditions for prospective sensemaking by disrupting existing knowledge structures and weakening a retrospective orientation, participatory mechanisms of exploring possible futures, and the refinement, testing and materialisation of new understandings and ideas. The second contribution is to the emerging research on prospective sensemaking and the role of artefacts in such processes. While current theorisations of sensemaking predominantly focus on retrospective forms, our study sheds light on the practices that support prospective sensemaking through specific features of thinking infrastructures, and we unpack how prospective and retrospective forms of sensemaking may interact in such processes.

The challenge to account for the unexpected: Thinking infrastructures in unstable environments

With an early theoretical interest in the possible roles of technologies and systems, such as accounting devices, in unstable environments, Cooper et al. (1981, p.187) observed that: 
Organisations require adaptability, flexibility and the ability to create variety in order to survive in changing, variated environments. In contrast to this flexibility, the organisation requires a technology for maintaining some consistency and intelligent behaviour. In terms of effectiveness we wish to emphasise that organisations characterised by ambiguous goals, unclear technology and fluid participation need not be pathological.

Cooper et al. (1981) recognise the role of accounting systems as ordering technologies that can facilitate the rationalisation of actions and provide a sense of organisational consistency. At the same time, organisational objectives are conceptualised as the outcome of action rather than their determining factor, which poses challenges for the potential of accounting systems to work as thinking infrastructures that go beyond ex-post legitimation and aspirational notions of representation (Mouritsen \& Kreiner, 2016). This research raised questions on the design of such systems to not only sensitise organisations to reporting on ambiguities and inconsistencies, but also to facilitate more radical notions such as experimentation and goal discovery in unstable environments (Cooper, 1983). The contours of this agenda were further sketched out by March (1987), who encouraged enquiry into accounting system design and practice, highlighting the potential power of ambiguity in enhancing procedures and systems to transform what is knowable.

Such interest in processes of adaptation, emergence and variation have since stimulated productive inquiry in several areas of research. In a study on the management of large-scale projects with multiple stakeholders and complex goal structures, Boland, Sharma \& Afonso (2008) suggest that in such environments, performance measurement and control systems become influential if they help decision-makers generate novel, previously unknown alternatives, instead of focusing on meeting pre-existing choices and metrics. In a study on the Balanced Scorecard (BSC), Busco \& Quattrone (2015) explore elements that enable its continuous unfolding and adjustment to organisational variation. Busco \& Quattrone (2015) theorise on the capacity of the BSC, as a material artefact, to engage the user thanks to its features that offer a visual performable space, a method of ordering as well as mediation, and a motivating ritual. This research highlights the importance of technologies that facilitate a continuous search for options within the emergent variety of context-dependent constraints, implying that new alternatives have to be invented and old ones adapted. 
In line with such arguments, Mouritsen \& Kreiner (2016) explore how accounting may be implicated in providing the conditions for adjustments and adaptations in decision-making processes, thereby conceptualising decisions as 'promises' instead of endings that stop such unfolding processes. Lorino, Mourey \& Schmidt (2017, p.2) further investigate the relationship between performance metrics as "generic meaning frames" and the way these numbers are engaged in "malleable local framing and (re)framing processes" to engage with organisational change. For Lorino et al. (2017), the possibility for re-framing resides in the dual nature of performance metrics, which are both contextually situated and generically modelled. Accordingly, as managers engage with inconsistencies between the situated value and the model, frameshifts become possible, allowing for ongoing adaptation to organisational change. These findings also share important connections with literature highlighting the possibly conducive nature of incompleteness for the situated practice of measures (Dambrin \& Robson, 2011; Chenhall, Hall \& Smith, 2013), and their flexible use in the engagement with organisational diversity (Jordan \& Messner, 2012). Accordingly, if measures are treated as means rather than ends, they are likely to be perceived as enabling tools to foster reflection-inaction.

However, despite these insights, theoretical understanding of how performance evaluation systems can serve as a thinking infrastructure that enables groups to build new understandings in collective processes of future-oriented sensemaking to engage with unstable environments, remains underdeveloped. In particular, little is known about the practices that underpin interaction with performance evaluation systems in the engagement with unexpected cues and their gradual transformation into more refined understandings. Such processes are of particular importance in environments where the potentialities for disastrous errors are overwhelming, such as humanitarian crisis, where organisations have to maintain a constant preoccupation with unexpected failure sources and limitations embedded in ongoing practices and systems (Weick \& Sutcliffe, 2015). To explore how evaluation systems may be implicated in such processes, we draw from sensemaking theory, and in particular, we investigate a thus far underexplored link between research on prospective sensemaking and the role of performance evaluation systems as constitutive elements of such sensemaking processes.

\section{Sensemaking Theory}


Over the last decades, sensemaking has become one of the central topics for the study of organising processes (see Weick, 1995). As Maitlis \& Christianson (2014) emphasise, despite the heterogeneity of research approaches to sensemaking, it can be broadly described as "the processes through which people work to understand issues or events that are novel, ambiguous, confusing, or in some way violate expectations.” In other words, sensemaking occurs when people are confronted with situations or tasks that evade interpretation through existing, taken-for-granted knowledge structures, measures, and systems. Sensemaking is simultaneously an interpretive and constitutive process through which an unfolding situation is grasped and partly determined through actions ensuing from its discovery. From this perspective, organising is conceived of as a constant sensemaking process in which people attempt to impose order on discrepancies between a state of the world as expected, and as it appears to be through recursive cycles of enactment, selection, and retention (Weick, 1995).

In line with such concerns, a range of empirical studies has investigated sensemaking processes within the context of unstable environments and crises that prompt a search for explanations of dynamically unfolding events. As Weick (1988, p.305) specifies, acting in crisis commonly entails the dilemma of choosing between "dangerous action which produces understanding and safe inaction which produces confusion." Studies identified several key elements facilitating sensemaking in such situations. These include clarity of role structures within groups (Weick, 1993), quality of team interactions (Weick \& Roberts, 1993), or an ability for re-orientation (Christianson, Farkas, Sutcliffe \& Weick, 2009). Other studies have drawn attention to elements impeding sensemaking processes that ultimately led to crisis intensification, including the gradual normalisation of anomalous cues, or an over-commitment to a single existing frame of interpretation (Cornelissen, Mantere \& Vaara, 2014). Boin et al. (2005, p.32) further problematise a common retrospective orientation as one of the key factors impeding sensemaking in crisis situations:

One of the most frequently used short cuts is the reliance on historical analogies to make sense of the challenges posed by a contemporary crisis. In [...] these circumstances, there is a clear pitfall associated with applying the presumed "lessons" of one crisis to another: crises might look similar, but they are unique by definition.

In particular, Boin et al. (2005) draw attention to the importance of leadership in setting up, developing, and cultivating communicative mechanisms for collective sensemaking in organisations. Combined, these studies highlight how sensemaking is often shaped by 
communicative and conversational issues, and is commonly theorised as occurring retrospectively.

\section{Prospective Sensemaking, Artefacts and Thinking Infrastructures}

Building on previous literature on the retrospective orientation of sensemaking, in recent years another important line of research emerged, exploring processes through which people seek to deal with ambiguous and confusing situations that require the construction of new ways of understanding in order/how to engage in future-oriented thinking (Stigliani \& Ravasi, 2012; Kaplan \& Orlikowski, 2013). Such forms of prospective sensemaking are particularly relevant for organisations that frequently operate in risky settings, in which the anticipation and construction of projective futures are a central exercise to avoid stumbling from one dangerous situation to the next. Gioia \& Mehra (1996, p.1229) outline some of the key elements surrounding retrospective and prospective forms of sensemaking as follows:

Retrospective sense making is targeted at events that have transpired; prospective sense making is aimed at creating meaningful opportunities for the future. In a loose sense, it is an attempt to structure the future by imagining some desirable (albeit ill-defined) state $[\ldots]$ prospective sense making is thus much more tentative.

Engaging with such arguments, sensemaking studies have argued that people can only assign meaning to events that have already occurred (Weick, 1995). From this perspective, prospective sensemaking is seen to happen when people engage in future perfect thinking, which describes a process through which an expected future state is envisaged and acted upon as if it had already transpired. However, such assumptions about future perfect thinking are problematic as they understate the ambiguity that is commonly associated with exploratory processes in the engagement with unstable settings: "thinking in future perfect tense [...] seems less appropriate to explain prospective cognitive work when expectations or aspirations about the future are ambiguous or unclear" (Stigliani \& Ravasi, 2012, p.1250-1251). Accordingly, in this paper we focus our theoretical interest on how people construct new knowledge structures and speculative futures that provide an impetus for action beyond future-perfect thinking in a more open-ended manner.

Following such lines of inquiry, a range of studies has begun to shed light on the ways material artefacts and infrastructures may support prospective sensemaking (see Stigliani \& 
Ravasi, 2012). This body of research suggests that traditional sensemaking approaches with a narrow focus on conversational practices resulted in a theoretical blind spot regarding the way artefacts may be implicated in the collaborative development of new understandings and in shaping the conversational practices that constitute sensemaking processes (Maitlis \& Christanson, 2014). As emphasised by Orlikowski \& Scott (2008, p.466), a focus on the material dimensions of sensemaking allows for a richer approach to understanding the key role of artefacts and material cues in collaborative interaction and meaning construction: "attention has tended to focus on [...] processes of sensemaking and interaction with little recognition of the deeply constitutive entanglement of humans and organisations with materiality." Against this background, research has begun to explore the role of artefacts in assisting in the materialisation of sensemaking work, with a focus on relatively simple artefacts, such as drawings (Bechky, 2003) or thumbnails and sketches in product design (Stigliani \& Ravasi, 2012).

Such concerns with the constitutive role of artefacts share important points of connection with research on sensemaking in accounting. Studies have drawn attention to the role of accounting as a formal rule system guiding sensemaking (Boland \& Pondy, 1983), and in facilitating organisational diagnosis (Boland, 1984), as well as the way readers use accounting texts to attribute meaning to an organisation and its history (Boland, 1993). More recently, Cooper et al. (2018, p.4) have drawn attention to importance of "historical understandings in retrospective sense-making involved in making various PMS legitimate." Accordingly, the roles of performance measurement systems in guiding sensemaking processes are acknowledged in the literature, and studies have drawn attention to aspects ranging from processes of legitimation to organisational history and identity.

Despite the contributions discussed above, scholarly understanding of the interaction between prospective and retrospective forms of sensemaking remains underdeveloped in organisation and management theory. Furthermore, even though studies have provided important insights on how relatively simple artefacts may shape and guide prospective sensemaking, little is known on the way performance evaluation systems may become implicated in such processes and provide a thinking infrastructure that guides organising work. The exploration of how thinking infrastructures can foster prospective sensemaking is particularly central in unstable organisational contexts such as humanitarian crisis, in which 
failure to anticipate dangers and possibilities do not uncommonly result in deaths, the marginalisation of vulnerable groups, or the prolonging of conflict.

\section{Methodology}

\section{Research Setting and Case Study}

As the site for our empirical research, we selected a large-scale refugee camp in the Middle East (hereafter anonymised as EmergencyResponse) that was set-up to manage an ongoing humanitarian crisis. As Flyvbjerg (2006, p.229) argues, a promising approach when selecting a research setting is to focus on the identification of a critical example which has "strategic importance in relation to the general problem." Our research interest in the management of EmergencyResponse was inspired by the instability and quickly unfolding nature of the setting, which presented specific challenges for collective sensemaking practices and performance evaluation. As EmergencyResponse's population grew to tens of thousands of people within a few months after the outbreak of the humanitarian crisis, it started experiencing significant issues surrounding the provision of essential services, the marginalisation of vulnerable groups, criminal activities and security, becoming one of the most unstable locations in its area. As a result, the humanitarian managers confronted a high degree of ambiguity regarding how future solutions for the camp should look like and how emergent cues from the unfolding response should be evaluated and made sense of, especially given that contextually reliable baselines for the operation were not clear-cut. Accordingly, the setting provided appropriate conditions to investigate how thinking infrastructures may inform managers in collective sensemaking challenges, ranging from interpreting emerging cues and exploring tentative future options, to recognising and elaborating contextual opportunities.

As previously stated, the emerging literature on prospective sensemaking suggests that artefacts can offer a material anchor and thinking infrastructure to support sensemaking by making cues, ideas and emerging connections between concepts, more persistently available for collaborative processes (Stigliani \& Ravasi, 2012; Bechky, 2003). In line with this body of work, in this study we focus our attention on the most widely used humanitarian performance evaluation system: The Sphere Handbook. We refer to Sphere both in relation to its material status as a handbook and its functioning as a thinking infrastructure that enables categorisations, classifications, evaluation and the orchestration of distributed cognition in the dynamic humanitarian environment. The material and movable nature of the Handbook is not 
trivial, as in humanitarian emergencies the information infrastructure requirements are commonly fragmented due to their unstable nature. In this sense, both its material and infrastructural properties are essential to understand the practices through which Sphere is put to work in humanitarian emergencies.

Sphere was developed in 1997 with the aim to create a system for evaluation and planning of performance in humanitarian crises. This process was driven by two of the largest European and North American humanitarian umbrella organisations, InterAction and the Steering Committee for Humanitarian Response. The development of Sphere has been described as the largest ever consultation on humanitarian performance. An important feature of Sphere is its focus on a handbook design, which was conceived so that humanitarian managers could carry it with them as an accessible "reference tool" (Sphere Handbook, 2011, p.10) into all types of field operations. Accordingly, focusing on the way Sphere became implicated in the attempts to engage with the ongoing challenge of managing the humanitarian crisis response, constitutes an appropriate selection to explore how artefacts, such as Sphere's handbook, may support sensemaking practices.

We studied the practical engagement with Sphere in the context of a central problem in the humanitarian response operation, namely the organisation of and evaluation practices surrounding the provision of nutritional supplies. While the delivery of nutrition constitutes one of the most consequential tasks of humanitarian crisis management, the intensity of the performance evaluation challenges faced by the managers in this area emerged as a key concern during the field research. Providing nutritional supplies does not only constitute a vital undertaking to ensure survival, but it reaches deep into many aspects of life in the refugee camp. These include cultural expectations, the inclusion of vulnerable groups, safety concerns, control, and inter-group politics. Due to the pressure that underlies the need to deliver basic services reliably under evolving circumstances, conducting a case study on the evaluative practices surrounding the issue of nutrition constituted an appropriate approach for the theoretical interests of this paper.

\section{$\underline{\text { Data Collection }}$}

Empirical material was collected from July 2014 to November 2015. During this time, twenty-eight semi-structured interviews and several hours of observations of organizing and evaluation practices were carried out in the refugee camp that the first author visited. These 
observations include work-shadowing of engineering teams, attendance of meetings and collection of a variety of reports and governance frameworks from the refugee camp. Participants included camp managers, field managers, evaluation officers, emergency coordinators, engineers, and community organisers. Follow-up interviews with six of the participants were conducted over a period of twelve months over the phone. Almost all interviews were digitally recorded and supplemented by note-taking. Upon transcription two interviews were found to be inaudible due to faulty technology. However, the central arguments were recovered through a combination of field notes and memory. Another important element of the data collection was informal conversations before and after the interviews, which provided further insights into the issues raised during the interviews. To keep track of the multitude of information sources and impressions, a notebook was kept, which was translated into a written narrative (Czarniawska, 2014). To complement our understanding of the setting, we further collected publicly available documents, including policy documents, opinion pieces and newspaper articles about the refugee camp and the performance evaluation system.

\section{Data Analysis}

Following Eisenhardt (1989), our analysis encompassed ordering the data chronologically (including interview transcripts, notes taken from participant observation and documents) to identify themes and patterns. The data analysis focused on frequently repeated statements that referred to how the evaluation system was used, and why it became influential in the sensemaking processes. We then compared the responses with statements from other participants involved in managing the situation. As it emerged from our analysis that different features from the evaluation system became influential during different phases, we reorganised our analysis to account for the way the evaluation system interacted with and shaped sensemaking processes. Consistent with this approach, the analysis proceeded by re-arranging the data around central emerging problems (e.g., the unrest in the camp and notions of refugee dignity), then connecting them with other relevant themes (e.g., clashes between technofinancial framings and participatory evaluation requirements), to comprehend critical issues surrounding the interaction between evaluation practices and sensemaking. The analysis then proceeded by relating these themes to issues in the literature, permitting a shift back and forth between empirical data and theory in a triangulating manner. The process continued until we felt that a point had been reached where there was an adequate fit between the empirical data, theory and the research problem. 


\section{Collective Sensemaking and Thinking Infrastructures in a Large-Scale Humanitarian} $\underline{\text { Crisis }}$

The case study takes place in EmergencyResponse, a large-scale refugee camp in the Middle East. As thousands of refugees arrived every night over a period of several months, the camp was under significant pressure to accommodate such large amounts of people for a prolonged period. In the case study, we focus on specific thinking infrastructures that enabled managers to evaluate actions and deal with the instability presented by the operational requirements of organising a large-scale humanitarian response operation in an ongoing manner. It is recognised that the capacity to deal with crises is dependent on infrastructures and artefacts that were developed before chaos unfolds (Weick \& Sutcliffe, 2015). Since crisis settings constitute their everyday operating environment, humanitarian organisations have developed particular systems that are designed to confront the sensemaking challenges surrounding the instability of such conditions. In this section, we further introduce the most widely used system of this kind and explore how it relates to humanitarian practice: The Sphere Handbook. A principal aim of Sphere is stated in an introductory passage:

The Sphere Handbook is designed for use during humanitarian response in a range of situations, including natural disasters, conflict, slow-and rapid-onset events, rural and urban environments, and complex political emergencies in all countries. [...] Effective humanitarian response must be based on a comprehensive, contextualised diagnosis (assessment, monitoring and evaluation), in order to analyse people's needs, vulnerabilities and capacities in each context. The Handbook is essentially designed as a tool to recognise different contexts and to adapt response programmes accordingly: it guides practitioners in their reflections around reaching a universally applicable standard in a concrete situation or context (Sphere Handbook, 2011, pp. 9-11; bold added).

Several terms stand out from this quote: adaptation, design, contextualisation, reflection, and recognition. These terms and their interrelationships raise several questions: How can Sphere's system be generally applicable while requiring a contextualisation that considers the variations of each humanitarian crisis? How might it facilitate reflection and interpretation of emergent challenges? To understand how and why Sphere is influential in crisis settings, it is informative to explore how its philosophy conceives of evaluation. Sphere conceptualises the abstract idea of humanitarian performance among four different dimensions of evaluation, thereby embracing multiple aspects that are at play during humanitarian action. These include ethics, technical issues, process quality, and protection. Table 1 summarises 
Sphere's four key evaluative dimensions on the horizontal axis and specifies some of its evaluation metrics on the vertical axis.

Take in Table 1

What is notable about Sphere's approach is that it moves away from the ideal of alignment (see Stark, 2009), and does not specify how the relationship between each evaluative dimension should be enacted in context:

All the chapters are interconnected. Standards described in one sector need to be addressed in conjunction with standards described in others. [...] The Handbook does not offer practical guidance on how to provide certain services (the key actions suggest activities to reach a standard without specifying how to do that). [...] The Sphere Project has consciously opted for the Handbook not to be prescriptive or compliance oriented (Sphere Handbook, 2011, p. 8, bold from original).

As each evaluation dimension builds on the other, their associative logic is interdependent, drawing attention to the way they complement and compete for attention and resources. Building on the experience of past humanitarian operations, Sphere recognises that humanitarian action cannot be reduced to a single techno-financial dimension but is defined by interlinked yet incommensurable evaluation dimensions. For instance, Sphere recognises that a narrow focus on the technical aspects of humanitarian response operations may not only create blind spots about how aid affects communities, but it also risks reducing disasteraffected populations to passive, dependent and voiceless aid recipients. Each of Sphere's evaluative dimensions is therefore conceived as not only as interlinked but also as irreducible. As we show throughout the case, the engagement with competing evaluation criteria has important implications into how the practice of the Handbook provides a thinking infrastructure that supports the diagnosis of issues and their interpretation in collective sensemaking processes.

One of the key areas around which conflicts and violence frequently surfaced in the response operation was the management of nutritional programs. Some of the challenges of setting up nutritional supply were initially addressed by reference to Sphere's technical evaluation dimension, and particularly its $2100 \mathrm{kcal}$ indicator, which provides an estimation of the minimum caloric requirements per person per day. However, while Sphere specifies 
indicators for each evaluation dimension, it emphasises that none of these categories should be considered in isolation, thereby seeking to prevent a dogmatic way of engaging with measures:

There has been this challenge that people want to reduce Sphere to a mere set of indicators [...] There have been discussions within Sphere in the past, so why don't we just put all the indicators in one list, so people have it easily accessible what they need to meet. Sphere would never do that. The idea is not to provide a checklist [...]. The problem is if you do a half an hour crash course, the tendency for engineers is to ask 'what are we actually talking about [in terms of indicators]?' They can get frustrated when the response is 'it's not just that, guys' (humanitarian response manager 3).

A key aim of Sphere's philosophy is thus to enable humanitarians to move beyond a 'checklist' approach to make sense of the humanitarian crisis in an ongoing manner. However, it was precisely in relation to this concern that some of the pressing issues of the crisis response started to emerge. While the managers had begun to approach the crisis with a narrow focus on technofinancial measures, the dangers of following a reductionist approach soon became evident:

There was a discrepancy between the issues that for once we could deliver on [Sphere's] main survival indicators and yet [EmergencyResponse] was a very unsafe place with unhappy people. The technical measures did not match with the psyche of the people [...]. When I came everybody said: we achieved everything, so why are they unhappy? Why are they rioting, why are they throwing stones? (camp manager 1).

The evidence stresses that in unstable and fast evolving environments, too much trust in measures (see Porter, 1995) risks creating blind spots that can proliferate in the way people make sense of the unfolding situation. By over-relying on pre-existing performance measures, emergent unexpected observations are often quickly connected to existing metrics, thereby contributing to their retrospective normalisation and rationalisation. In line with these insights, the following sub-sections explore how engagement with Sphere's system facilitated a move away from a reductionist approach to gradually make sense of the fast-changing dynamics of the humanitarian crisis.

Breaking away from a reductionist approach: The role of Sphere's evaluative tensions in making sense of the unexpected

The clash between the approach taken and the unrest that followed offer an opportunity to investigate the ensuing sensemaking challenges, as they forced the managers to reconsider what was at stake around the organisation of the crisis response. Against this background, 
Sphere offered a thinking infrastructure to make sense of the ill-defined challenges as the managers tried to engage with the unfolding situation.

To practicalise Sphere, we put overall sector working groups in place. [...] We looked at Sphere, at the conditions on the ground, and then we started to discuss required actions and recommendations on what we needed to do. Then they are reviewed and presented to camp management (camp manager 2).

However, rather than pre-specifying fixed performance objectives, Sphere's approach should be translated to stimulate new contextual understandings through the engagement with its evaluative dimensions:

The numbers alone miss the whole ways of looking at well-being. [...] I know some people think Sphere is a Magna Carta, but I think it is a catalyst. The context changes very quickly, and the context should define and will influence what happens. You take evaluative principles and ethics, and you apply them to the new context, and something comes out. It's a question about what sense you make out of it. That's where it becomes a powerful catalyst in the hands of an informed actor on the ground (humanitarian response manager 3 ).

In this context, Sphere became an important material artefact to be used in the working groups to prompt questioning and articulation of challenges and future options, which gradually helped to narrow down concerns as they engaged in sensemaking practices. This process enabled managers to assess their understanding of the challenges surrounding each evaluation dimension - involving issues of equitable distribution, quality, technical and financial elements, community preferences, and other factors affecting implementation. However, enacting Sphere in the working groups resulted in emerging tensions concerning its different evaluation dimensions:

Having [Sphere's] multiple performance criteria competing for our attention is improving performance because it is keeping these checks in play and it is keeping the humanitarian body on guard on what we are supposed to be doing (camp manager 2).

Accordingly, one issue was to understand how Sphere's competing performance requirements are connected and what kind of trade-offs existed between them. In this context, Sphere process-oriented prescriptions to evaluation served as an influential tool to shift manager's focus towards detecting gaps in understanding. Engagement with evaluative tensions in turn 
shaped sensemaking process by sensitising managers to blind-spots and vulnerabilities in the existing approach to aid delivery:

The big question became: how can we support people in that desire to allow the difference in a situation in which we must deal with masses and big numbers and logistics? [...] The problem is that you are rarely equipped to deal with all of [Sphere's] different performance requirements (camp manager 1).

In the sensemaking literature an overreliance on existing knowledge structures and ways of framing - as opposed to openness to question and explore alternative frames - has been identified as an essential source of sensemaking failure, especially in situations that require flexibility and adaptation (Cornelissen et al., 2014). In our case, the weakening of the reliance on existing performance metrics through the engagement with evaluative tensions constituted an important precondition to subsequently foster more anticipatory forms of sensemaking, which we further explore in the next section.

Several points can be summarised at this point about Sphere's influence on how managers made sense of and constructed new tentative understandings about the response operation. Firstly, contextualising Sphere's evaluation dimensions in the sector working groups helped managers to move towards a more holistic approach to evaluation and conceptualising of the camp as an integrated social space. Technical and social evaluative dimensions were no longer treated as separate but as co-constitutive. Secondly, in the process of exploring challenges, tensions between Sphere's dimensions played an important role for several reasons. Focusing on tensions opened-up spaces to explore inconsistencies and contextual cues from the operation, thereby stimulating exploration of links among elements that were not prescribed a priori in the evaluation system. Evaluative tensions hereby attracted users because they drew attention beyond what could be represented through the system (see March, 1987), which constituted an important element to foster the pre-conditions for more future-oriented forms of sensemaking to emerge subsequently.

From retrospective reflection to exploring tentative new understandings: Evaluation as a participatory process

Making sense of the unexpected entails acknowledging the limitations of existing knowledge structures in capturing the range of response requirements in humanitarian crises. 
However, it takes specific thinking infrastructures, such as Sphere, to anticipate emergent issues before they become impossible to contain. While Sphere specifies that it can never be met without involving affected communities in the evaluation processes, this prescription was one of the key elements missing in the response operation:

To ensure the appropriateness and quality of any response, the participation of disasteraffected people [...] should be maximised. [...] The extent to which people participate will be determined by how recently the disaster occurred and by the physical, social and political circumstances. Indicators signaling participation should be selected according to context and represent all those affected (Sphere Handbook, 2011, pp.148156).

The guidelines surrounding participation build on an important implication of navigating the dynamic humanitarian environment: the impossibility of pre-specifying problems, and to identify predefined alternatives and solutions. Since Sphere encourages the set-up of parallel structures for information gathering, additional communication channels emerged thanks to this engagement.

Now there is a very significant dynamic in the camp for community participation [...] All the partners meet with the refugees in groups [...] Refugees are holding us accountable, they are participating in the decision-making in the camp, and we are holding them accountable, telling them 'if you expect us to do this then these are your responsibilities'. This is telling us how we are performing on a regular basis (camp manager 2).

Accordingly, the gradual construction of participatory evaluation practices included the set-up of mechanisms for the refugee community to hold agencies to account; channels through which communities can hold their representatives to account, and mechanisms through which agencies can hold communities to account. Without an in-depth understanding of demands from the community, no constructive account of and tentative solution for the response operation's challenges would be possible:

Left to our own devices, we tend to shut out the people who are receiving our assistance. We wouldn't need to have things like Sphere if people saw the importance of regarding people at the center of humanitarian action (evaluation officer 1).

These mechanisms rearranged the previous top-down mode of organising the camp, providing a way through which the refugee community was included in collective sensemaking processes. The participatory mechanisms were also important in gaining additional information sources, 
enabling the co-construction of new tentative understandings about the situation in the camp to engage more seriously with the isolation of vulnerable groups, the drivers of violence, and the lack of autonomy and choice.

However, fostering participatory processes was far more than a mere technical exercise. The question of refugee participation is complicated due to at least two interrelated reasons. Firstly, there are no well-established community structures. A sense of community has to be carefully developed over time. Secondly, aid services are delivered in the absence of clear accountability structures, in which refugees can provide feedback on the quality received:

Now we have regular formal and informal consultations with refugees. The formal consultations take the form of regular meetings with the refugee representatives, whereby we consult them on various issues, from the quality of the services in the camp to future plans. We can involve them in the planning, distributions for example. This is the only way the assistance is made sustainable. [...] A refugee camp is imagining a new community settling down. If you apply [Sphere] in an environment that itself is not conducive, you will not be necessarily meeting the needs of the people. So, it's very important that refugees are involved in the planning, in choosing types of assistance (camp manager 3).

While there is no straightforward way of resolving these issues, Sphere's prescriptions on participatory processes stimulated reflection on the elements through which community outreach mechanisms would need to be enacted in the future.

We would invite the street leaders and have a discussion with them. Of course, they are self-appointed. After we engaged in discussion with them we realised that it's probably not a very good idea to keep in direct contact with them because it was empowering them and there is a risk that they will act as information gatekeepers (field manager 2).

Accordingly, abusive structures emerging from within the community emerged as an important problem for the response operation. By flexibly translating Sphere's guidelines to the contextual requirements, novel pathways of organising the participatory mechanisms emerged.

To address the issue of abusive structures we created a 'rotational map.' Within each block, they had to meet and agree on twelve members. Among those members, we would have six members that would monitor [performance]. And this is done on a rotational basis to ensure that every household that wants to be represented can be represented and to ensure that people do not dominate (camp manager 2). 
In light of the evidence, participatory practices evolved into an influential mechanism to shape collective sensemaking processes that played a central role in the reorganisation of the camp. While Sphere's performance categories served to organise the terms of engagement of such collective sensemaking processes, the categories remained open to redefinition. Enacting evaluation as a participatory process not only provided additional information sources for managers, but it offered a channel for refugees to voice concerns, thereby reducing oversimplification and taking into account different perspectives and groups throughout the camp.

Implicating thinking infrastructures in co-constructing and materialising new understandings: Contextualising Sphere and adapting to the variability of the humanitarian crisis

As Weick \& Sutcliffe (2007, p.67) emphasise, constructing new meanings in conditions of instability requires the capacity "to sense the unexpected in a stable manner and yet deal with the unexpected in a variable manner." This section focuses on the practices through which Sphere became implicated as a thinking infrastructure in co-constructing new meanings and 'solutions' to tackle some the humanitarian response operation's problems. In this context, one of the important requirements of any future solution was implied in the emerging understanding that the fixed way of distributing nutritional supplies produced unintended outcomes:

There was the problem that some big guys managed to get hold of some of the ration cards of people that were not in the camp anymore. That meant that they were selling the food rations, making [thousands of] dollars each day [...] So, that in fact made people vulnerable to the crooks, the people that managed to get hold of the stuff and then sold them on (camp manager 1).

EmergencyResponse's managers found themselves in a paradoxical situation in which the aid they delivered contributed to illegal activities and the emergence of criminal groups that seized aid items and developed a profitable business by trading these goods. It thus became clear that a novel solution for the organisation of nutrition required an approach that would integrate the interrelated issues surrounding protection and violence, isolation of vulnerable groups, and cost-effectiveness. However, while the participatory evaluation practices had opened up spaces for refugee engagement and trust-building, any possibility to gain community acceptance for new solutions depended on the ability to instigate processes of inter-group sensemaking (Maitlis \& Christianson, 2014) between humanitarian managers and refugees. 
Accordingly, constructing a novel solution was not only linked to functional considerations of meeting evaluative metrics, but it involved a symbolic element that would indicate that the refugee's concerns had been heard:

Meeting Sphere's quantitative indicators was never a big problem in principle, but speaking of dignity [...] so let's say, I lost my home, I lost half of my family members, and I ran away with my wife and my daughter. Now I am not used to someone say 'now you are going to eat this and that'. Now I am in a camp, so of course, I have to queue, and it's not even the food that I like. Begging for food that they don't want to eat is not dignity for the refugees (field manager 2).

In this context, Sphere's prescriptions surrounding the notion of human dignity can become an important trigger for action. Yet, since dignity is not defined in essentialist terms by Sphere, it can only be conceived in relation to its other evaluative dimensions:

When you are working with people, the right to a life with dignity then suddenly gets kind of fluffy [...] Then you hold up the [Sphere] Handbook and say 'this entire book is an attempt to articulate what that means.' It is about looking at these four technical chapters. But it is also about the how of aid provision [...] and all the qualitative indicators throughout that refer to who has the right to participate in decisions and who should be consulted, and these other soft measures of quality (field manager 1).

Resonating with literature that stresses the importance of artefacts in group- and inter-group sensemaking (Stigliani \& Ravasi, 2012; Maitlis \& Christianson, 2014), Sphere's prescriptions on human dignity and on counteracting an overly dogmatic manner of working with measures, became an important mechanism through which humanitarians and refugees guided their contextual interactions. These interactions were no longer predominantly concerned with a strict focus on metrics, but instead on 'striking the right tone' in upholding a stream of communication between different groups. Sensemaking processes hereby became inseparably linked with sensegiving, the process through which people seek to shape the sensemaking of others (Gioia \& Chittipeddi, 1991):

Let me give you an example of how flexibility matters. The current delivery amounts slightly fall below the actual needs on the ground as per the assessment of our partners. This changes the technical indicators [...] Sphere guides us in this process of negotiating [...] This gives us the opportunity to have a direct feel from the refugees. The refugees are not interested in my indicator (camp manager 2 ). 
Thus, in these inter-group sensemaking processes between humanitarians and refugees about appropriate performance and reasonable solutions, plausibility became more important than accuracy (Weick, 1995). Due to the heterogeneous and unpredictable range of issues across humanitarian crises, an evaluation system that over-specifies response requirements would be quickly overwhelmed by contextual variations. However, as Weick \& Sutcliffe (2007, p.58) argue: "Although categories are unavoidable, we can carry them more lightly." Carrying performance categories more lightly implies that they can be treated as pretexts to investigate cues and blind spots in sensemaking processes, serve as a mechanism to question the expectations that underlie these categories and compare them with observations. This, for instance, occurred when the humanitarian managers realised that criminal groups seized a significant portion of the nutrition items they were delivering.

Building on the emerging understandings regarding the violence, the managers conducted an extensive analysis of aid delivery in the camp to make sense of alternative future ways of organising nutrition. As part of the aid analysis, a nutrition operations team came forward with the proposal to begin a gradual transition away from the distribution of standardised food parcels towards distributing vouchers that could be redeemed at markets inside the camp. Following the articulation of this tentative 'solution,' EmergencyResponse's managers began exploring its potential to plausibly link several key concerns. Firstly, it promised a tighter integration of two important performance requirements, namely Sphere's measures of technical efficiency and its ethical evaluation concerns:

They push their trolley, and they buy the food they actually want. You may see it as a normal thing. But no, if you go to the supermarket and you see the pride refugees feel there. The father will get together with the mother and take their kids and go shopping. Before they felt like begging for food. But when you go to the supermarkets, you can understand it: the dignity of 'I am buying this because I want it' (field manager 2).

Accordingly, organising nutritional supplies in this novel way through vouchers allowed the community to regain a limited sense of choice and dignity. Furthermore, this reorganisation of nutrition freed EmergencyResponse's managers from having to handle mass distributions at fixed points in time:

Instead of refugees having to queue up for half a day to get food ration we moved away from this. Now we don't do in-kind food donations. We now give them a voucher they can redeem at the two supermarkets (field manager 2). 
This not only "reduced overhead costs significantly" (camp manager 2), but also allowed for reinvestment into ration allowances for food vouchers. Without mass distributions, the gatherings that led to some of the most violent situations could be avoided. Not only was the 'aid market' easier to secure but eliminating the feeling of 'begging for food' made refugees less likely to react violently and prevented unwanted goods landing on black markets. This novel contextual 'solution' is now put forward as a social innovation to be considered in humanitarian crises around the world. However, it is important to re-emphasise that this study's focus does not lie on particular results of humanitarian crisis management, which are always partial and temporary. Instead, our emphasis is on the way Sphere offered a thinking infrastructure to guide engagement with the instability of humanitarian crises that create the possibilities for options to emerge.

\section{$\underline{\text { Discussion }}$}

Our research question led us to explore the roles thinking infrastructures such as Sphere can play in shaping processes of prospective sensemaking to engage with unstable environments. In what follows, building on our empirical material, we develop a theorisation on the constitutive roles the Sphere's system played during different sensemaking phases. By unpacking the dynamics and interrelationships between the system and these phases, our study further develops understanding about the recent interest in the role of artefacts as constitutive elements in the practices that underpin prospective sensemaking (Stigliani \& Ravasi, 2012; Maitlis \& Christianson, 2014).

Fostering conditions for prospective sensemaking: The role of evaluative tensions in thinking infrastructures

Studies have drawn attention to the problematic nature of performance metrics in creating a 'tyranny of transparency' (Strathern, 2000), where measures do not provide a channel for knowledge exploration, but instead serve as mechanisms through which important organisational phenomena are eclipsed and hidden. In the engagement with unstable environments, too much trust in numbers and metrics (Porter, 1995; Espeland \& Stevens, 1998) can lead to what Weick (2005) calls 'failures of imagination,' in which an overly strict focus on fixed measures inhibits what people can see, envision, and conceive. Such failures of imagination were particularly evident in our case when the refugee camp drifted into chaos at 
the beginning of the humanitarian response. As managers resorted to a narrow set of technofinancial metrics, a stream of information and early-warning signs that did not fit the measures was overlooked or marginalised. Accordingly, the use of performance measures holds the risk to induce people to quickly classify emergent phenomena as 'in-family' (Weick, 2005), namely as events that had been previously experienced and analysed, which contributes to their gradual rationalisation and normalisation. Quick normalisation, in turn, encourages a retrospective orientation where even events that defy expectations are made to fit into well-known, available knowledge systems (Weick \& Sutcliffe, 2015; Boin et al., 2005). For example, our evidence indicated how managers struggled with and initially ignored the observation that although most technical measures on collective nutritional requirements were met, the camp gradually moved into disarray, suggesting that technical measures were unsatisfactory to make sense of the situation.

Accordingly, weakening the tendency to seek normalisation (Boin et al., 2005) when using measures, is an important precondition to foster more future-oriented forms of sensemaking. In our case, a critical element that destabilised the retrospective orientation of employing measures related to the evaluative tensions (see Stark, 2009) that frequently surfaced as managers interacted with Sphere. While aid delivery is often defined by a technical evaluation focus, engaging with Sphere reminded managers that humanitarian response operations are not just about keeping people alive in hostile environments. Instead, aid delivery involves essential but less quantifiable evaluation dimensions of returning a sense of participation, autonomy, and dignity to refugees. Accordingly, establishing connections between Sphere's techno-financial and ethical criteria was simultaneously complementary and challenging in practice. On the one hand, reconstructing a limited sense of dignity required managers to meet necessary technical measures. On the other hand, as the emergence of criminal groups showed in the case, meeting Sphere's technical measures for the camp's nutrition requirements gave managers little insight on the way powerful groups affect access by vulnerable people. Accordingly, exploring tensions between Sphere's interlinked yet incommensurable frameworks of evaluation proved to be a challenging undertaking that destabilised an overly rigid reliance and trust in existing metrics.

In line with these insights, Stigliani \& Ravasi (2012, p.1249) suggest that fostering conditions for prospective sensemaking requires acknowledging the insufficiency of pre- 
existing knowledge structures, such as performance measures, which have to be disrupted as a result:

The novelty or ambiguity of the circumstances that trigger sensemaking would suggest that available mental structures are not appropriate to explain the situation those circumstances comprise. New structures need to be constructed or new linkages need to be traced among available structures.

Disrupting existing knowledge structures does not constitute an easy or intuitive task. Refining them is a demanding process that requires a guiding thinking infrastructure, as managers need to go back and forth between emergent cues based on retrospective reflections and the construction of new tentative connections with a more forward-oriented perspective. In our case, the tensions between evaluative principles not only guided managers towards moving away from a reductionist techno-financial approach, but they were also influential in encouraging questioning of desired but ill-defined future options. Engaging with evaluative tensions was challenging for the humanitarian managers. However, tensions between Sphere's evaluative dimensions attracted users during initial processes of sensemaking because they introduced guided ways of expressing doubt on existing observations, while opening up spaces for exploration beyond what was knowable at that point.

While Weickian approaches to sensemaking mainly highlight the importance of conversational elements (Weick et al., 2005; Weick, 1995), they tend to focus less on the role of artefacts, such as the Handbook, in providing an important thinking infrastructure that can shape unfolding collective sensemaking processes. This interest in artefacts also resonates with research stressing the importance of the 'format and furniture' of information systems and accounting technologies in engaging the user, and the silent epistemology that is embedded in them which guides interactions (Pollock \& D’Adderio, 2012; Quattrone, 2015). Adding to such lines of enquiry, in this section we discussed how establishing conditions for prospective sensemaking partly depended on weakening an overly trusting approach to existing performance metrics, which induced a retrospective orientation contributing to quick normalisation of observations. We highlighted how the persistent, collective engagement with evaluative tensions, were implicated in creating the preconditions to foster processes of prospective sensemaking. 
Once tentative understandings about matters of concern emerged, organising work shifted to the exploration of new possible futures for the humanitarian crisis response. As shown in section 5.2 of our case, the interaction with Sphere's prescription of refugee participation evolved into a mechanism to move away from conceiving of organising as a rigid and top-down process towards more decentralised and distributed forms. In this context, the participatory mechanisms helped to understand, channel and re-constitute the power relations inherent in collective sensemaking processes (Maitlis \& Christianson, 2014). Establishing such participatory processes against the background of the complicated dynamics within the camp community, implied a need to organise a form of openness that enabled the managers to be responsive and stay in motion: "real openness implies that a system is open to information that it has never thought of before" (Kramer, 2007, p.75). To explain how such openness may be organised as part of a thinking infrastructure, in this section we develop the notion of open and participatory design and discuss how it became implicated in shaping collective sensemaking processes.

As described in the case, a key reason for establishing Sphere's prescriptions on refugee participation was to prevent the marginalisation of vulnerable groups and counteract the aid system's susceptibility to treat refugees as passive aid recipients with no agency and voice. In past aid operations, humanitarians had frequently been criticised for paying insufficient attention to such concerns. For example, during the 1994 humanitarian response to the Rwanda genocide, such a lack of attention to the socio-cultural dynamics within disaster-affected populations, was linked to the provision of aid to genocidaires, who used camps to organise military attacks (Barnett, 2011). The lessons from Rwanda drew further attention to the risks of treating disaster-affected communities as unified groups while disregarding people's local capacities and the ability for resistance. These experiences are in line with the emergence of criminal groups in our case, who not only seised aid items but also contributed to the increasing levels of violence. Accordingly, these lessons highlight a need for thinking infrastructures that stimulate attention to unintended effects that are often produced when interfering in unstable social settings (see Weick \& Sutcliffe, 2015).

Against this background, Sphere's prescriptions on participatory evaluation offered an important sensemaking resource (see Maitlis \& Christanson, 2014) to engage refugee groups with otherwise little formal power, and to enable them to exercise some influence over the construction of new, tentative visions for the camp. Open and participatory evaluation practices 
hereby served as a practical and symbolic mechanism for trust building amongst the camp community and humanitarians. While it was clear that notions of increased community participation, autonomy, and dignity were significantly restrained in the camp context, our findings indicated that even the attempt to pursue these notions served as a signal for the refugee community that their concerns were acknowledged. The conventional way of centralised aid provision with standardised items was not only perceived as humiliating, but it also contributed to violent protests and the emergence of criminal groups seising unwanted aid items. Given that much relevant information was not to be found in the formal systems, open and participatory practices offered insights from heterogeneous groups with different expectations. For example, without the participatory mechanisms, it would have been impossible to find out about the black markets for aid items and the mechanisms through which vulnerable groups became further marginalised. Such arguments resonate with observations by Maitlis \& Christanson (2014, p. 98), who emphasise "the importance of a variety of sensemaking resources, of which formal authority is only one," and who stress the need for an enquiry into the tussles of collective sensemaking processes (Brown, 2000, 2005). Accordingly, these participatory processes offered channels to make visible, and mitigate, struggles that form essential parts in collective sensemaking processes.

Since Weick et al.'s (2005) observation that sensemaking theorisations have to become less politically naïve, studies have problematised how different groups compete to shape processes of meaning construction or attempt to undermine or change the status quo (see Brown, 2005). These studies have also highlighted a need for a more nuanced theorisation of sensemaking resources and infrastructures (Maitlis \& Christianson, 2014) that guide collective sensemaking. Adding to such concerns, the notion of open and participatory design draws attention to the role of thinking infrastructures as sensemaking resource that offer ways of channelling engagement between groups with different levels of influence. In our case, the participatory evaluation processes helped to build trust, to reconstruct a limited sense of dignity, and to source insights from different groups without which the tentative construction of future visions for the camp would have been complicated. In so doing, it also sheds light on how evaluative systems may embrace techniques that broaden the focus beyond their contextual limitations (March, 1987; Mouritsen \& Kreiner, 2016) and thereby open up spaces for collective enquiry that enable groups to engage in sensemaking processes. However, our case also indicated the risks of such open and participatory processes. To partly mitigate the dangers of consolidating pre-existent abusive power structures enforced by criminal groups, 
more elaborate forms of participation had to be established. These included rotational mechanisms in which community representatives changed on a regular basis as well as the numerous community outreach officers and that provided a dynamic monitoring system attuned for the engagement with the unfolding dynamics of the humanitarian response.

\section{Refining, testing and materialising: Performance measures as sensegiving resources}

As new visions for EmergencyResponse emerged through the sensemaking practices, organising work gradually shifted towards refining and materialising these novel understandings into more concrete propositions. Such new propositions involved ensuring that none of Sphere's evaluative dimensions would be persistently prioritised over the others in their translation to the particularities of the camp. Specifically, these concerns became linked to the need to break the influence of criminal groups and their ability to manipulate participatory evaluation processes to their advantage.

In this phase of refining and testing, forms of sensemaking and sensegiving became inseparably connected. As highlighted by Gioia \& Chittipeddi (1991, p.442), sensegiving is "the process of attempting to influence the sensemaking and meaning construction of others toward a preferred redefinition of organisational reality." In our case, EmergencyResponse's managers mobilised several elements from Sphere to guide sensegiving processes. In particular, Sphere's prescriptions on the need for contextualisation and adjustment of measures frequently emerged as an important element that fostered a preoccupation with extracting new cues (see Weick \& Sutcliffe, 2015) to anticipate problematic developments in the engagement with the refugee community. For example, the humanitarian managers recursively collected information from community organisers to reflect on their newly gained contextual understanding of Sphere's ethical and protection measures in EmeregncyResponse until it became clear that the 'aid delivery market solution' was interpreted as a sign of pragmatic respect by the community.

The ongoing focus on contextualisation of measures shares connections, but also differs in several aspects, with studies that have drawn attention to the dual nature of performance metrics as both generically-modelled and contextually-situated (Lorino et al., 2017; Boland et al., 2008). For example, while Lorino et al. (2017) describe how contextualisation of metrics instigated shifts in framing, in our case, it served as a precondition to stimulate situational sensitivity and responsiveness in negotiations surrounding inter-group sensegiving processes 
between managers and refugees. Sphere's prescriptions of contextualisation encouraged an attitude that facilitated not only ongoing preoccupation with revisions and tentative linkages, but also stimulated action-based enquiry to interpret and update emerging cues from the community. In other words, for Sphere to serve as a resource in such inter-group sensemaking and sensegiving processes (see Gioia, \& Chittipeddi, 1991), it had to work against an overly fixed and dogmatic approach in using its measures.

Accordingly, the 'aid delivery market' was not only understood as a way of decentralising aid distribution to fulfil evaluation metrics, but it also served as a symbol for the community indicating that their voice had been heard. These considerations resonate with the observation that sensemaking processes are stimulated as people engage in retrospective reflections to assess the "plausibility of prospective accounts by reconstructing the chain of thought leading to them" (Stigliani \& Ravasi, 2012, p.1251). In our case, the ongoing reflection on the 'aid delivery market' proposition did not only serve the purpose of establishing its plausibility. Importantly, these reflections also helped to keep communication channels with different groups open to ensure that the proposed 'solution' continued to be accepted. In line with such arguments, our analysis sheds further light on how retrospective and prospective forms of sensemaking may not be incompatible but can be mutually reinforcing, as well as how artefacts such as Sphere's handbook may guide such interactions as groups engage in sensemaking practices.

\section{Conclusion}

Our study on organising practices in a large-scale humanitarian crisis helped us to provide a detailed account of features that enabled Sphere's evaluation systems to provide a thinking infrastructure that shaped processes of prospective sensemaking in unstable environments. In addressing these issues, our study provides two theoretical contributions. Existing research has offered insights in the way such systems can help reframing in response to organisational change (Boin et al., 2005; Lorino et al., 2017), enable adjustments to deal with variability (Mouritsen \& Kreiner, 2016; Cooper et al., 1981), or create contextual opportunities (March, 1987). However, our study suggests that existent theorisations offer only a partial understanding of how thinking infrastructure become implicated in the collective construction of new understandings in unstable environments. Our study begins to unpack the practices this process relies upon and sheds light on how specific features, from the thinking 
infrastructure, guided the transformation of collective understandings and interactions in the unfolding humanitarian crisis. These processes include fostering conditions for prospective sensemaking by disrupting existing knowledge structures and weakening a retrospective orientation, participatory mechanisms for exploring possible futures, and the refinement, testing and materialisation of new understandings and ideas.

The second contribution of our study is to the emerging research on the interaction between prospective and retrospective sensemaking and the role of material artefacts and infrastructures such as Sphere in these processes (Sitgliani \& Ravasi, 2012; Kaplan \& Orlikowski, 2013). Studies interested in the material aspects of sensemaking have so far mainly focused on relatively simple artefacts (Bechky, 2003) that extend the capacity of individuals and groups to make sense of novel and ambiguous cues. Building on such insights, our study enhances scholarly understanding of the practices that support prospective sensemaking, through specific features of thinking infrastructures, to amplify the capacities of groups in the collaborative construction of new understandings over time. In particular, we shed light on the material underpinnings of prospective sensemaking (Maitlis \& Christianson, 2014) by showing how artefacts can offer a material anchor in group processes, making cues and emerging connections between concepts more enduringly available to shape continuous collaborative sensemaking work, in the ambiguity and unpredictability that commonly defines large-scale humanitarian crises. 


\section{Acknowledgments}

The authors are grateful for the help and advice of Martin Kornberger, Andrea Mennicken and Neil Pollock who provided helpful comments on drafts of this paper. We would also like to express our gratitude to the following people for providing valuable suggestions and ideas during the writing process. These include: Paolo Quattrone, David Cooper, Iris Bosa, Silvia Jordan, Stephen Walker, Shaul Hayoun, Jakov Jandrić and Daniela Toledo Machado. We are also grateful to the participants of various departmental seminars where this study has been presented (Refugee Studies Centre - University of Oxford; University of Innsbruck School of Management; Cambridge Judge Business School).

\section{References:}

Barnett, M. (2011). Empire of Humanity: A History of Humanitarianism. New York: Cornell University Press.

Bechky, B. A. (2003). Sharing meaning across occupational communities: The transformation of understanding on a production floor. Organization Science, 14, 312-330.

Beckert, J. \& Bronk, R. (2018). Uncertain Futures: Imaginaries, Narratives, and Calculation in the Economy. Oxford: Oxford University Press.

Boin, A., Hart, P., Stern, E. \& Sundelius, B. (2005). The politics of crisis management: Public leadership under pressure. Cambridge: Cambridge University Press.

Boland, R. J. (1984). Sense-making of accounting data as a technique of organizational diagnosis. Management Science, 30 (7), 868-882.

Boland, R. J. (1993). Accounting and the interpretive act. Accounting, Organizations and Society, 18, 125-146.

Boland, R. J., \& Pondy, L. R. (1983). Accounting in organizations: a union of natural and rational perspectives. Accounting, Organizations and Society, 8 (2), 223-234.

Boland, R. J., Sharma, A. K. \& Afonso, P. S. (2008). Designing management control in hybrid organizations: The role of path creation and morphogenesis. Accounting, Organizations and Society, 33 (7), 899-914. 
Brown, A. D. (2000). Making sense of inquiry sensemaking. Journal of Management Studies, 37 (1), 45-75.

Brown, A. D. (2005). Making sense of the collapse of Barings Bank. Human Relations, 58 (12), 15791604.

Burchell, S., Clubb, C., Hopwood, A.G., Hughes, J. \& Nahapiet, J. (1980). The roles of accounting in organizations and society. Accounting, Organizations and Society, 5 (1), 5-27.

Busco, C., \& Quattrone, P. (2015). Exploring how the balanced scorecard engages and unfolds: articulating the visual power of accounting inscriptions, Contemporary Accounting Research, 32 (3), 1236-1262.

Chenhall, R., Hall, M., \& Smith, D. (2013). Performance measurement, modes of evaluation and the development of compromising accounts. Accounting, Organizations and Society, 38 (4), 268287.

Christianson, M. K., Farkas, M. T., Sutcliffe, K. M., \& Weick, K. E. (2009). Learning through rare events: Significant interruptions at the Baltimore \& Ohio Railroad Museum. Organization Science, 20 (5), 846-860.

Cooper D. J. (1983). Tidiness, muddle and things: commonalities and divergencies in two approaches to management accounting research. Accounting, Organizations and Society, 8 (2/3), 269-286.

Cooper, D. J., Hayes, D., \& Wolff, F. (1981). Accounting in organized anarchies: understanding and designing accounting systems in ambiguous situations. Accounting, Organizations and Society, $8(2 / 3), 269-286$.

Cooper, D. J., Ezzamel, M. \& Robson, K. (2018). The multiplicity of performance management systems: Heterogeneity in Multinational Corporations and management sense-making. Contemporary Accounting Research. Forthcoming.

Cornelissen, J., Mantere, S, \& Vaara, E. (2014). The contraction of meaning: The combined effect of communication, emotions, and materiality on sensemaking in the Stockwell shooting. Journal of Management Studies, 51(5), 699-736.

Czarniawska, B. (2014). Social Science Research: From Field to Desk. London: Sage Publications.

Dambrin, C. \& Robson, K. (2011). Tracing performance in the pharmaceutical industry: ambivalence, opacity and the performativity of flawed measures. Accounting, Organizations and Society, 36 (7), 428-455.

ECBP (2007). The good enough guide: Impact measurement and accountability in emergencies. London: Emergency Capacity Building Project.

Eisenhardt, K. M. (1989). Building theories from case study research. Academy of Management Review, 14 (4), 532-550. 
Espeland, W. N., \& Stevens, M. L. (1998). Commensuration as a Social Process. Annual Review of Sociology, 24, 313-343.

Flyvbjerg, B. (2006). Five Misunderstandings about case study research, Qualitative Enquiry, 12 (2), 219-245.

Garud, R., Sanjay, J. \& Tuertscher, P. (2008). Incomplete by design and designing for incompleteness. Organization Studies, 29, 351- 371.

Gioia, D. A., \& Chittipeddi, K. (1991). Sensemaking and sensegiving in strategic change initiation. Strategic Management Journal, 12 (6), 433-448.

Gioia, D., Thomas, J., Clark, S. \& Chittipeddi K. (1994). Symbolism and Strategic Change in Academia: The Dynamics of Sensemaking and Influence. Organization Science, 5 (3), 363383.

Gioia, D. A., \& Mehra, A. (1996). Sensemaking in organizations - Weick, K. E. Academy of Management Review, 21, 1226-1230.

Hällgren, M., Rouleau, L., \& de Rond, M., (2018). A matter of life or death: How extreme context research matters for management and organization studies. Academy of Management Annals, $12(1), 111-153$.

Jordan, S. \& Messner, M. (2012). Enabling control and the problem of incomplete performance indicators. Accounting, Organizations and Society, 37 (8), 544-564.

Kaplan, S., \& Orlikowski, W. J. (2013). Temporal Work in Strategy Making. Organization Science, 24 (4), 965-995.

Kornberger, M., Pflueger, D. \& Mouritsen, J. (2017). Evaluative infrastructures: Accounting for platform organization. Accounting, Organizations and Society, article in press.

Kramer, E. (2007). Organizing doubt: Grounded theory, army units and dealing with dynamic complexity. Copenhagen: Copenhagen Business School Press.

Lorino, P., Mourey, D., \& Schmidt, G. (2017). Goffman's theory of frames and situated meaningmaking in performance reviews. The case of a category management approach in the French retail sector. Accounting, Organizations \& Society. Article in press.

Maitlis, S. \& Christianson, M. (2014). Sensemaking in Organizations: Taking stock and moving forward. Academy of Management Annals, 8 (1), 57-125.

March, J. G. (1987). Ambiguity and accounting: the elusive link between information and decision making. Accounting, Organizations and Society, 12 (2), 153-168.

Miller, P. \& O'Leary, T. (2007). Mediating instruments and making markets: capital budgeting, science and the economy. Accounting, Organizations and Society, 32 (7-8), 701-734. 
Mouritsen, J., \& Kreiner, K. (2016). Accounting, decisions and promises. Accounting, Organizations and Society, 49 (2), 21-31.

Orlikowski, W. J., \& Scott, S. V. (2008). Sociomateriality: Challenging the separation of technology, work and organization. Academy of Management Annals, 2 (1), 433-474.

Pollock, N. \& D'Adderio, L. (2012). Give me a two-by-to matrix and I will create the market: rankings, graphic visualization and sociomateriality. Accounting, Organizations and Society, 37 (8), 565586.

Porter, T. M. (1995). Trust in Numbers: The Pursuit of Objectivity in Science and Public Life. Princeton: Princeton University Press.

Power, M. (2007). Organized Uncertainty: Designing a World of Risk Management. Oxford: Oxford University Press.

Quattrone, P. (2015) Value in the age of doubt: Accounting as a maieutic machine. In Kornberger, M., Justesen, L., Mouritsen, J., \& Madsen, A. K. (Eds.). Making things valuable. Oxford: Oxford University Press.

Quattrone, P. \& Hopper, T. (2005). A time-space odyssey: Management control systems in two multinational organizations. Accounting, Organizations and Society, 30 (7-8), 735-764.

Sphere Handbook (2011). The Sphere Handbook. Available at: < http://www.sphereproject.org/resources/downloadpublications/search=1\&aid=nne $>$ Accessed on 27 January 2014.

Stark, D. (2009). The Sense of Dissonance: Accounts of Worth in Economic Life. Princeton: Princeton University Press.

Stigliani, I., \& Ravasi, D. (2012). Organizing thoughts and connecting brains: Material practices and the transition from individual to group-level prospective sensemaking. Academy of Management Journal, 55 (5), 1232-1259.

Strathern, M. (2000). The tyranny of transparency. British Educational Research Journal, 26 (3), 309321.

Weick, K. E. (1988). Enacted sensemaking in crisis situations. Journal of Management Studies, 25 (4), 305-317.

Weick, K. E. (1993). The collapse of sensemaking in organizations: The Mann Gulch disaster. Administrative Science Quarterly, 38 (4), 628-652.

Weick, K. E. (1995). Sensemaking in organizations. Thousand Oaks, CA: Sage Publications.

Weick, K. E. (2005). Organizing and Failures of Imagination. International Public Management Journal, 8 (3), 425-438. 
Weick, K. E., \& Roberts, K. H. (1993). Collective mind in organizations: Heedful interrelating on flight decks. Administrative Science Quarterly, 38, 357-381.

Weick, K. E., Sutcliffe, K. M., \& Obstfeld, D. (2005). Organizing and the process of sensemaking. Organization Science, 16 (4), 409-421.

Weick, K. E., Sutcliffe, A. (2007). Managing the Unexpected: Resilient Performance in an Age of Uncertainty. ( $2^{\text {nd }}$ ed.). Reading: Addison-Wesley.

Weick, K. E., Sutcliffe, A. (2015). Managing the Unexpected: Sustained Performance in an Age of Uncertainty. ( ${ }^{\text {rd }}$ Ed.). Reading: Addison-Wesley.

\section{INSERT ANY TABLES / FIGS / PICTURES / ILLUSTRATIONS / TABLES}

HERE (or attach them in separate documents) 
Table 1: Distinct modes of evaluation within the Sphere Handbook 


\begin{tabular}{|c|c|c|c|c|}
\hline & \multicolumn{4}{|c|}{ Evaluation Dimensions } \\
\hline & $\begin{array}{l}\text { Ethical Standards } \\
\text { (Humanitarian } \\
\text { Charter) }\end{array}$ & $\begin{array}{l}\text { Quality and } \\
\text { Process } \\
\text { Standards }\end{array}$ & $\begin{array}{l}\text { Technical Standards } \\
\text { (Selected) }\end{array}$ & $\begin{array}{l}\text { Protection } \\
\text { Standards } \\
\text { (selected) }\end{array}$ \\
\hline $\begin{array}{l}\text { Evaluation } \\
\text { Criteria }\end{array}$ & $\begin{array}{l}\text { Right to Live with } \\
\text { Dignity } \\
\text { Right to Receive } \\
\text { Impartial } \\
\text { Assistance } \\
\text { Right to Protection } \\
\text { and Security }\end{array}$ & 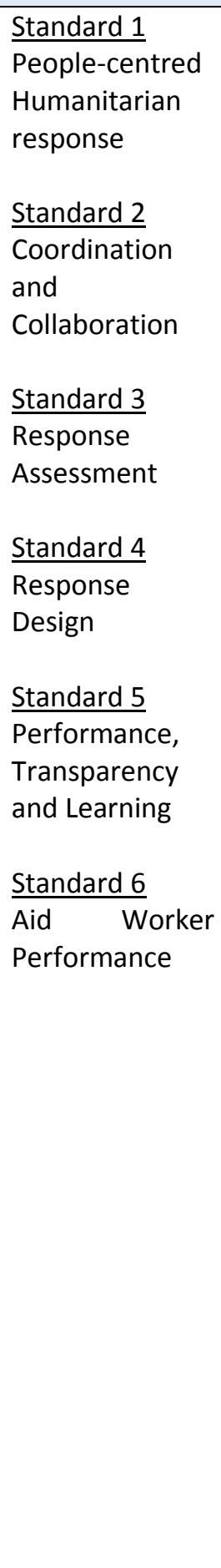 & 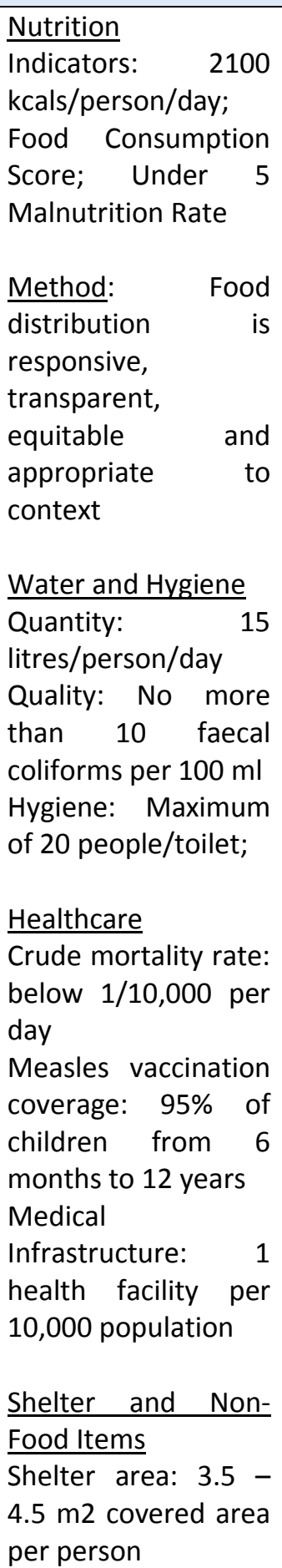 & 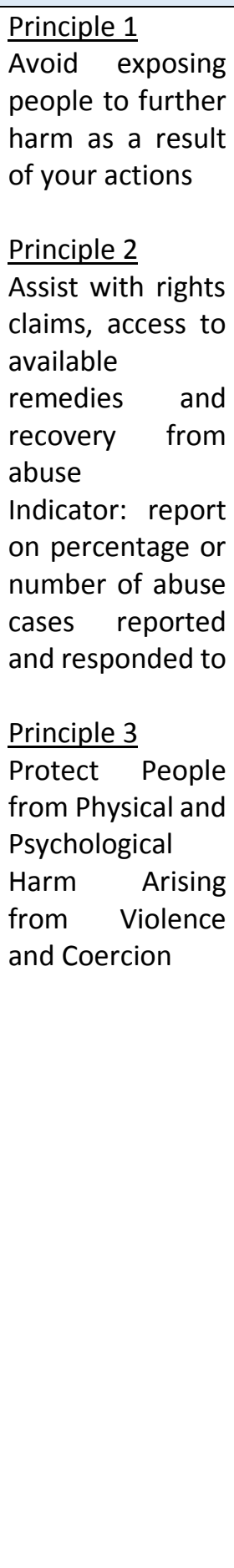 \\
\hline
\end{tabular}

